\title{
Polymorphism of the Complement Receptor for C3bi
}

Graeme R. Russ, Albert P. Haddad, Brian D. Tait, and Anthony J. F. d'Apice

Department of Nephrology, The Royal Melbourne Hospital, Victoria, 3050, Australia

\begin{abstract}
RM2.184, a mouse $\operatorname{IgG}_{2 a}$ monoclonal antibody, recognizes a polymorphic determinant on the complement receptor for $\mathrm{C} 3 \mathrm{bi}$ which is present on granulocytes and monocytes. The RM2.184 epitope is distinct from the monomorphic determinant recognized by the monoclonal antibody OKM1. The RM2.184 epitope is probably on the alpha subunit and dependent on the association of the alpha and beta subunits for its configuration, as it can not be detected after the subunits have been dissociated. The phenotypic frequency of the RM2.184 antigen is $\sim 14 \%$, and its segregation in families is independent of HLA and consistent with an autosomal co-dominant mode of inheritance.
\end{abstract}

\section{Introduction}

Recently, a family of three structurally and antigenically related human leukocyte differentiation antigens have been described. This family consists of the lymphocyte function-associated antigen-1 (LFA-1) ${ }^{1}$ (1), the complement receptor for C3bi (CR3) (2), and a p 150, 95 molecular complex (3). Each of these molecules consists of an alpha and beta subunit which is noncovalently associated. The beta subunits are all 95,000 mol wt and are apparently identical, but the alpha subunits vary in size, being 177,000, 165,000 and 150,000 mol wt for LFA-1, CR3, and $p 150,95$, respectively. Whereas the function of $p 150,95$ is unknown, both LFA-1 and CR3 play a role in adhesion between effector and target cells (1). CR3, which is expressed on the surface of monocytes, granulocytes, and natural killer cells, is thought to be of clinical importance, as the granulocytes of a patient prone to recurrent bacterial infections lacked this antigen $(4,5)$. The structure and cellular expression of this molecule have been largely established by monoclonal antibodies (MAb) to monomorphic determinants, and several of these antibodies, OKM1, OKM10, Mol, and Mac-1, have been reported to inhibit receptor binding of its ligand, $\mathrm{C} 3 \mathrm{bi}(2,3,6,7)$; however, there is disagreement about OKMl on this point (6). We have recently reported the production of an MAb, RM2.184, which recognizes a polymorphic determinant on monocytes and granulocytes (8).

Part of this work was was the subject of a preliminary report in Transplant. Proc. (1984. 16:944-945).

Address reprint requests to Dr. d'Apice.

Received for publication 31 December 1984.

1. Abbreviations used in this paper: CR3, complement receptor for $\mathrm{C} 3 \mathrm{bi}$; 2D, two dimensional; EAC, erythrocyte antibody complement; FITC, fluorescein isothiocyanate; GVB++, gelatin-veronyl buffer containing $0.3 \mathrm{M} \mathrm{CaCl}_{2}$ and $0.1 \mathrm{M} \mathrm{MgCl}_{2}$; LFA-1, lymphocyte function-associated antigen-1; MAb, monoclonal antibody(s); PAGE, polyacrylamide gel electrophoresis.

J. Clin. Invest.

(C) The American Society for Clinical Investigation, Inc. 0021-9738/85/11/1965/06 \$1.00

Volume 76, November 1985, 1965-1970
We report here on the characterization of the determinant recognized by this antibody which indicates that it is a polymorphic determinant on CR3.

\section{Methods}

Cells. Granulocytes were separated from heparinized blood $(10 \mathrm{U} / \mathrm{ml})$ of normal volunteers by sedimentation with dextran followed by Isopaque-Ficoll gradient sedimentation (9). Contaminating erythrocytes were lysed by 2 min exposure to $0.07 \mathrm{M}$ ammonium oxalate. Mononuclear cells were separated from heparinized blood by Isopaque-Ficoll density gradient sedimentation (9). T and B lymphocytes were separated by passage through a nylon wool column (10). Monocytes were separated from mononuclear cell preparations by adherence to fetal calf serum-treated plastic Petrie dishes with subsequent elution with $0.2 \%$ EDTA.

Monoclonal antibodies. Balb/c mice were immunized intravenously with $5 \times 10^{6}$ mononuclear cells from a single donor on two occasions $3 \mathrm{wk}$ apart. $4 \mathrm{~d}$ after the second immunization the spleens were removed and fused with the myeloma line $\mathrm{Sp} \mathrm{2/0-Ag} 14(11,12)$. Culture supernatants were screened for antibodies reactive with the $T$ and $B$ lymphocytes and monocytes of the immunizing donor by microcytotoxicity (13). Antibody-producing cultures were cloned repeatedly by limiting dilution until all wells with colonies produced antibody of the same reactivity pattern. The immunoglobulin class of cloned hybridoma supernatants was determined by immunodiffusion against immunoglobulin class and subclass specific antisera (Liton Bionetics, Kensington, MD). OKMI was purchased from Ortho Diagnostics (Raritan, NJ); MAb 4911.1, an $\mathrm{IgG}_{2 \mathrm{a}}$ antibody specific for mouse Ly-2.1 (14), was a gift of Prof. I. F. C. McKenzie (University of Melbourne, Australia). MOPC-173, an $\mathrm{IgG}_{2 \mathrm{a}}$ mouse myeloma, was a gift of Dr. J. Goding (Walter and Eliza Hall Institute, Melbourne, Australia). MAb WEM-G11, which recognizes a monomorphic determinant on a 95,000-mol wt molecule on human granulocytes, was a gift of Dr. M. Vadas (Walter and Eliza Hall Institute). RM7.30, a MAb recognizing a monomorphic determinant on HLA class I molecules, was produced in our laboratory.

Labeling, immunoprecipitation, and electrophoresis of cell surface proteins. Granulocytes were ${ }^{125}$ I-labeled by the lactoperoxidase method (15) and solubilized in $0.5 \%$ Triton X-100 containing $1.5 \mathrm{mM}$ phenylmethylsulphonylfluoride. Lysates were precleared with $200 \mu \mathrm{l}$ of $10 \%$ staphylococcus aureus (Pansorbin, Calbiochem-Behring Corp., San Diego, CA) before incubation with MAb. Immune complexes were precipitated with $200 \mu \mathrm{l}$ of $10 \% \mathrm{~S}$. aureus cells and dissociated with sodium dodecyl sulphate (SDS) buffer ( $0.2 \%$ SDS, $0.0625 \mathrm{M}$ Tris, $\mathrm{pH} 8.5)$ with or without $50 \mathrm{mM}$ dithiothreitol. The samples were subjected to SDS-polyacrylamide gel electrophoresis (PAGE) using 7.5\% polyacrylamide gels (16) and autoradiography with enhancing screens (17). In sequential immunoprecipitation experiments, labeled lysates were immunoprecipitated three times with one antibody and then immunoprecipitated with another antibody.

Two-dimensional (2D) electrophoresis. 2D electrophoresis with isoelectrofocusing in the first dimension followed by SDS-PAGE electrophoresis under nonreducing conditions in the second dimension was performed by the method of O'Farrell as described by Jones (16).

Dissociation of alpha and beta subunits. Three methods of dissociation were employed. (1) High pH (2). Aliquots of cell lysate were mixed with 10 -fold excess of solutions containing $50 \mathrm{mM}$ triethylamine, $0.1 \%$ Triton $\mathrm{X}-100$, and $0.5 \mathrm{M} \mathrm{NaCl}$, the $\mathrm{pH}$ of which had been adjusted with $\mathrm{HCl}$ or $\mathrm{NaOH}$ to produce solutions whose $\mathrm{pH}$ differed by $0.5 \mathrm{U}$ from $\mathrm{pH} 9-$ 12.5. After $30 \mathrm{~min}$ incubation at $0^{\circ} \mathrm{C}$, the samples were neutralized with predetermined volumes of $1 \mathrm{M}$ Tris- $\mathrm{HCl}$ to achieve a sample $\mathrm{pH}=7.6$. 
(2) Urea. Aliquots of cell lysate were mixed with an equal volume of phosphate-buffered saline (PBS) containing increasing concentrations of urea to yield final urea concentrations of from 1 to $4 \mathrm{M}$. (3) Affinity chromatography. Cyanogen bromide-activated Sepharose 4B (Pharmacia Fine Chemicals, Uppsala, Sweden) affinity columns were prepared with ammonium sulfate-precipitated MAb. Cell lysates were sequentially passed through a hydrolyzed Sepharose 4B-containing column, a column to which MAb 49-11.1 was bound (preclear), then through a column containing RM2.184 (18). The latter column was eluted with a stepwise pH gradient from pH 9-11.5 (19). Fractions were concentrated by precipitation with $-20^{\circ} \mathrm{C}$ acetone and centrifugation and resuspended in SDS sample buffer.

Immunoelectroblotting. Granulocyte lysates were subjected to SDSPAGE (10\% N, N diallyltardiamide gels). The proteins were then transferred to nitrocellulose membranes using the Trans-blot cell (Bio-Rad Laboratories, Richmond, CA). The transfer buffer was $25 \mathrm{mM}$ Tris, $192 \mathrm{mM}$ glycine, $\mathrm{pH} 8.3,20 \%$ methanol, and with or without $0.1 \%$ SDS. Two different protocols were used, either $22 \mathrm{~V}, 13 \mathrm{~mA}, 18 \mathrm{~h}$, or $55 \mathrm{~V}$, $270 \mathrm{~mA}, 2 \mathrm{~h}$. The nitrocellulose paper was cut into strips corresponding to SDS-PAGE lanes and were blocked with either $3 \%$ bovine serum albumin (BSA) (19) or 5\% high protein dry skim milk in PBS, Bovine Lacto Transfer Technique Optimizer (20). The membranes were probed with RM2.184, OKM1, and 302, followed by horseradish peroxidase conjugated rabbit anti-mouse antibody (Bio-Rad Laboratories). The substrate was 4 chloro-1-napthol with $\mathrm{H}_{2} \mathrm{O}_{2}$.

Radiobinding assays. MAb and $\mathrm{F}\left(\mathrm{ab}^{\prime}\right) 2$ fragments of goat anti-mouse IgG (Pel-Freeze Biologicals, Little Rock, AR) were ${ }^{125}$ I-labeled by the lactoperoxidase method. Binding assays were performed in microtitre trays using $100 \mu \mathrm{l}$ of granulocytes $\left(10^{7} \mathrm{cells} / \mathrm{ml}\right)$. For direct binding assays, ${ }^{125}$ I-labeled MAb were added $\left(10^{5} \mathrm{cpm} /\right.$ well $)$, incubated for $1 \mathrm{~h}$ at room temperature, and washed three times with PBS containing 5\% BSA and $0.02 \%$ sodium azide (PBS/BSA $/ \mathrm{NaN}_{3}$ ). For indirect binding assays, unlabeled MAb were added ( $100 \mu \mathrm{l}$ at $1 \mathrm{mg} / \mathrm{ml})$, incubated for $1 \mathrm{~h}$ at room temperature, and washed three times with $\mathrm{PBS} / \mathrm{BSA} / \mathrm{NaN}_{3}$, then incubated for $1 \mathrm{~h}$ with ${ }^{125} \mathrm{I}-\mathrm{F}\left(\mathrm{ab}^{\prime}\right) 2$ anti-mouse $\mathrm{IgG}\left(2 \times 10^{5} \mathrm{cpm} / \mathrm{well}\right)$ and again washed three times as above (21). Cells were resuspended by mechanical agitation, aspirated into counting vials, and bound radioactivity was counted. Competitive binding assays were performed by the direct binding method with prior incubation with excess unlabeled MAbs.

Flow cytometry. $10^{5}$ granulocytes in $20 \mu \mathrm{l}$ of PBS were labeled with $5 \mu \mathrm{l}$ of MAb at $20 \mu \mathrm{g} / \mathrm{ml}$, which was demonstrated to give saturation binding, washed, labeled with fluorescein isothiocyanate (FITC)-conjugated rabbit anti-mouse IgG (Tago Inc., Burlingame, CA), and washed by centrifugation through fetal calf serum. Fluorescence was measured by a FACS II (Beckton-Dickinson \& Co., Sunnyvale, CA).

Erythrocyte antibody complement $(E A C)$ rosettes. Ox erythrocytes were coated with a maximum subagglutinating amount of rabbit antiox erythrocyte-purified IgM. EAC were prepared from IgM-coated ox erythrocytes by incubation with zymosan-absorbed human serum (R3 reagent) (22) for $30 \mathrm{~min}$ at $37^{\circ} \mathrm{C}$, washed three times, and resuspended in gelatin-veronyl buffer containing $0.3 \mathrm{M} \mathrm{CaCl}_{2}$ and $0.1 \mathrm{M} \mathrm{MgCl}$ $(\mathrm{GVB}++) .0 .5 \times 10$ granulocytes were incubated with various amounts of the MAb RM2.184, OKM1, and 49.11.1 in a final volume of $150 \mu \mathrm{l}$ of RPMI 1640 , incubated at $37^{\circ} \mathrm{C}$ for $1 \mathrm{~h}$, washed three times, and resuspended in $800 \mu \mathrm{l}$ of GVB++ containing trypsin inhibitor (1.2 $\mathrm{mg} / \mathrm{ml}) .200 \mathrm{ml}$ of $1 \% \mathrm{EAC}$ was added, and after mixing and incubation for $15 \mathrm{~min}$ at $37^{\circ} \mathrm{C}$ the mixtures were centrifuged at $200 \mathrm{~g}$ for $5 \mathrm{~min}$. The cells were gently resuspended and rosette formation was assessed using phase-contrast/fluorescence microscopy with acridine orange counterstaining. At least 200 granulocytes were examined in each sample.

\section{Results}

Initial characterization of RM2.184 MAb. The supernatant from one well of a 400 -well fusion was found to react with the immunizing donor's monocytes-but not the T or B lymphocytesin a complement-dependent microcytotoxicity assay. The hy- bridoma was cloned and was of the $\operatorname{IgG}_{2 \mathrm{a}}$ subclass. Subsequent testing of RM2.184 showed that it reacted with monocytes of only 4 of 33 normal subjects. Immunohistological studies of lymph nodes and a variety of other tissues confirmed the polymorphic nature of the epitope detected, and showed that the molecule was present on monocytes, macrophages, and granulocytes, but not on other cells present in the sections (8). This distribution is identical to that described for CR3 (23).

Comparison of the molecules recognized by RM2.184 and OKM1. Both MAb immunoprecipitated molecules consisting of two noncovalently linked subunits (alpha, 165,000 mol wt; beta, 95,000 mol wt) (Fig. 1, lanes 1 and 2). 2D electrophoresis (first dimension iso-electric focusing, second dimension SDSPAGE) showed the isoelectric points of the two subunits precipitated by each antibody to be 6.0-6.2 (alpha) and 5.2-5.8 (beta). Sequential immunoprecipitation of a granulocyte lysate of the immunizing donor by OKM1 followed by RM2.184 showed complete clearance of the p 165, 95 bands by OKM1 and no subsequent precipitation by RM2.184. The reverse experiment gave identical results (Fig. 1, lanes 3-6 and 7-10, respectively), indicating that the MAb recognize the same molecule.

Relationship between the RM2.184 and OKM1 epitopes. Fig. 2 shows the results of a direct binding assay in which granulocytes of the immunizing donor were preincubated with unlabeled $\mathrm{MAb}$ (RM2.184 or OKM1), washed, and then incubated with ${ }^{125} \mathrm{I}$ labeled RM2.184 or OKM1. Neither MAb inhibited the binding of the other, which indicated that they detect different epitopes.

Effect of RM2.184 and OKMI on EAC rosetting. Fig. 3 shows the results of a representative experiment in which granulocytes of the immunizing donor were incubated with varying concentrations of MAb, washed, and rosetted with EAC. OKM1 caused a dose responsive inhibition of EAC rosetting while RM2.184 and the negative control MAb 49-11.1 had no effect.

Attempts at subunit localization of the epitope. SDS-PAGE electrophoresed ${ }^{125}$ I-labeled precipitates obtained with each antibody could be readily transferred to nitrocellulose paper by electroblotting. However, ${ }^{125}$ I-labeled RM2.184 and OKM1 which would bind to granulocytes of the immunizing donor would not bind to electroblotted unlabeled precipitates that had been transferred under a variety of conditions.

Aliquots of ${ }^{125}$ I-labeled granulocyte lysates were subjected to high $\mathrm{pH}$ to dissociate the noncovalently linked subunits, followed by immunoprecipitation, SDS-PAGE electrophoresis, and autoradiography. OKM1 precipitated both alpha and beta

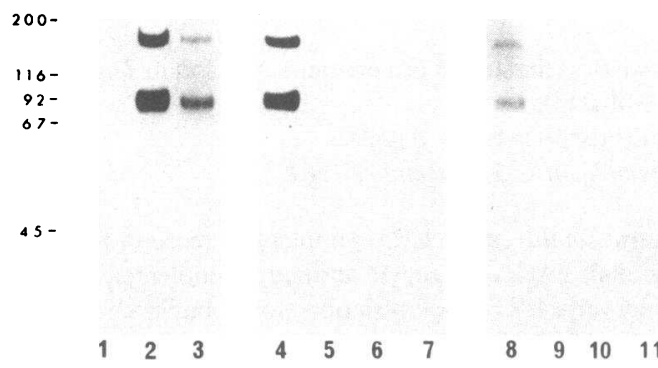

Figure 1. SDS-PAGE (7.5\% polyacrylamide gel) of granulocyte lysates of the immunizing cell donor immunoprecipitated by 49-11.1 (lane 1), OKM1 (2), and RM2.184 (3). 4-6 show the results of sequential immunoprecipitation of one sample of lysate by OKM1 followed by RM2.184 (7). 8-11 show the results of three sequential immunoprecipitations of a sample of lysate by RM2.184 followed by OKM1. 


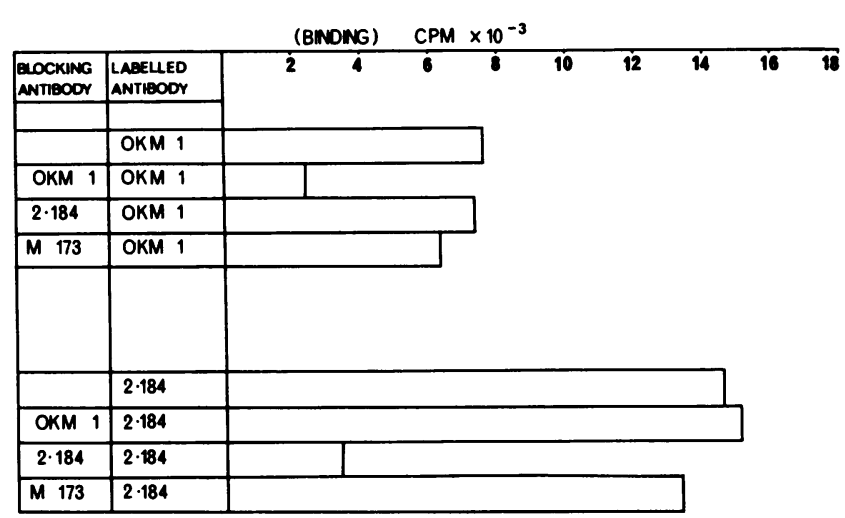

Figure 2. Binding inhibition assays showing that OKM1 and RM2.184 do not inhibit the binding of each other.

subunits when the $\mathrm{pH}$ of the dissociating solution was up to $\mathrm{pH} 11$; at pH 11.5-12.5, only the alpha subunit was precipitated. RM2.184 precipitates contained decreasing amounts of both alpha and beta subunits, with increasing $\mathrm{pH}$ of the dissociating solution, with no precipitate being present above $\mathrm{pH} 11$. Aliquots of ${ }^{125} \mathrm{I}$-labeled granulocyte lysates were subjected to increasing concentrations of urea (1-4 M) before immunoprecipitation. OKM1 precipitates were shown to contain only alpha subunits when the molarity of the urea solution was 3.5 and RM2.184 precipitates contained both subunits up to $3.0 \mathrm{M}$ urea, and no precipitate was obtained at higher concentrations.

${ }^{125}$ I-labeled granulocyte lysates were precleared by passage through a blank Sepharose 4B column, and through a column containing the irrelevant $\operatorname{IgG}_{2 \mathrm{a}}$ MAb 49-11.1 coupled to Sepharose 4B before passage through an RM2.184-containing affinity column which was eluted with solutions of increasing $\mathrm{pH}$. The eluates at each step were precipitated with acetone and subjected to SDS-PAGE electrophoresis. Eluates at pH 10-11.5 contained both alpha and beta subunits with no precipitates detected above $\mathrm{pH} 11.5$.

Thus, while the alpha subunit localization of the OKM1 epitope could be confirmed, the subunit localization of the RM2.184 epitope could not be demonstrated.

Polymorphism of CR3 detected by RM2.184. The initial observation that RM2.184 reacted with monocytes and granulocytes of a minority of the population (8) was further examined to determine the frequency of the RM2.184 (+) phenotype. Di-

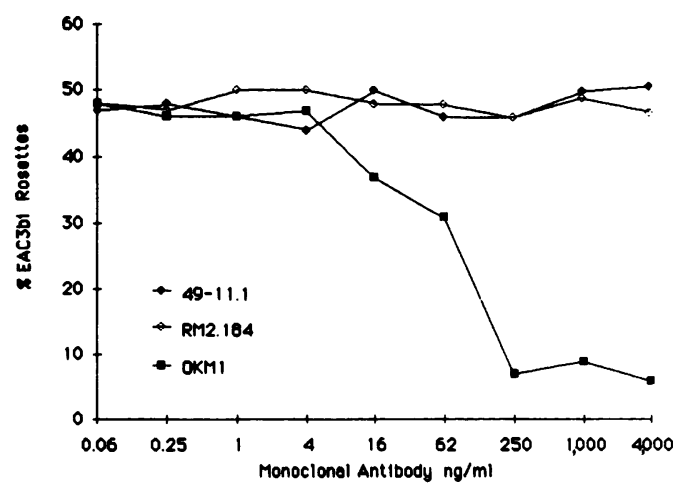

Figure 3. Effect of MAb RM2.184, OKM1, and 49-11.1 on EAC rosette formation by granulocytes of the immunizing donor.

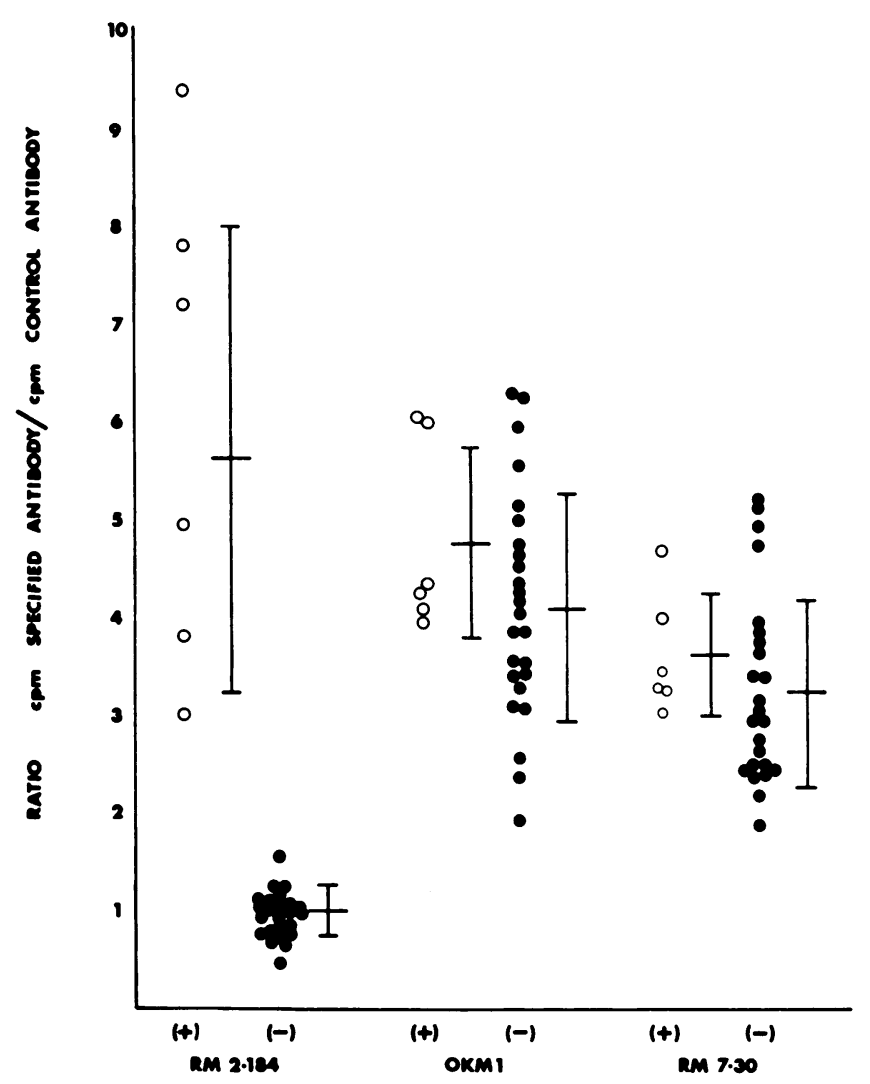

Figure 4. Indirect binding assays of granulocytes of 31 individuals of previously determined RM2.184 phenotype.

rect binding assays were performed on granulocytes from 51 unrelated normal adults. 10 were found to react with RM2.184 as assessed by the ratio of the counts bound by an individual's granulocytes to those bound by those of the immunizing donor, which were used as a control in each assay. The ratio was $0.43 \pm 0.13($ mean $\pm \mathrm{SD})$ for the positive population $(n=10)$ and $0.06 \pm 0.03$ for the negative population $(n=41)$. Binding of ${ }^{125} \mathrm{I}-\mathrm{OKM} 1$ was also examined with 13 of these cells. The ratio of binding of RM2.184 to that of OKM1 was 1.40-2.46 with five known RM2.184-positive cells, compared with 0.18-0.42

Table I. Indirect Immunofluorescence of Granulocytes with MAb

\begin{tabular}{lccc}
\hline & \multicolumn{3}{c}{$\begin{array}{c}\text { \% Granulocytes beyond chanel 80 after reaction with } \\
\text { MAb and FITC-F(ab'2 }\end{array}$} \\
\cline { 2 - 4 } Subject anti-mouse Ig & \\
\cline { 2 - 4 } & MOPC-173 & WEM-G11 & RM2.184 \\
\hline $1^{*}$ & 1 & 65 & 89 \\
2 & $<1$ & 30 & 80 \\
3 & $<1$ & 57 & 2 \\
4 & 2 & 54 & 2 \\
5 & $<1$ & 60 & 49 \\
6 & 1 & 63 & 99 \\
7 & $<1$ & 57 & 3 \\
8 & 1 & 47 & 3 \\
9 & $<1$ & 41 & 1
\end{tabular}

* Immunizing cell donor. 


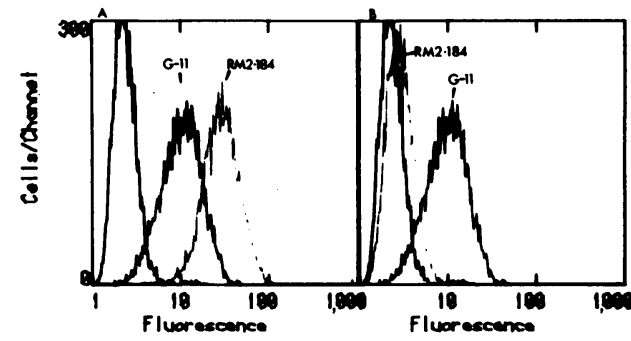

Figure 5. Flow cytometric analysis of the binding of MOPC-173 (unlabeled), WEM-G11, and RM2.184 to granulocytes of RM2.184-positive $(A)$ and -negative $(B)$ subjects.

for the eight negative cells. Indirect binding assays with granulocytes were performed using MAb and ${ }^{125} \mathrm{I}$-labeled $\mathrm{F}\left(\mathrm{ab}^{\prime}\right) 2$ goat anti-mouse Ig as the second antibody. 31 individuals whose RM2.184 phenotype had been determined by the direct binding assay were studied. The results were expressed as the ratio of the counts obtained with the specified MAb to those obtained with the unreactive control myeloma protein MOPC173 (Fig. 4). There was a clear distinction between RM2.184 (+) and ( -$)$ cells. The difference between the positive and negative populations was not due to a quantitative difference in CR3 density, as OKM1 binding was similar in both groups. Granulocytes from 10 subjects whose RM2.184 phenotype had previously been determined were examined with RM2.184, OKM1, and G11 by indirect immunofluorescence and flow cytometry. The results are summarized in Table I and the fluorescence profiles of two representative cells are shown in Fig. 5.

In total, 130 unrelated individuals were tested in one or more assays. No discrepancies were found within or between the different assays. 18 individuals were RM2.184(+), which represents a phenotypic frequency of $14 \%$.
Family studies. Granulocytes from 20 members of three families in which one parent was RM2.184 (+) were studied with the direct binding assay. The levels of binding of RM2.184 and OKM1 were assessed simultaneously. The RM2.184 phenotype was independent of the simultaneously measured OKM1 binding, which was high with the granulocytes of all family members. RM2.184 reactivity segregated independently of HLA and was consistent with an autosomal dominant or co-dominant mode of inheritance (Fig. 6).

Sequential immunoprecipitation of RM2.184 heterozygous granulocytes. Granulocyte lysates were prepared from three individuals who were shown by family studies to be obligate heterozygotes. In each case, sequential immunoprecipitation by OKM1 followed by RM2.184 showed complete clearance of the p 165, 95 bands by OKM1 and no subsequent precipitation by RM2.184. However, when the order of precipitation was reversed, despite complete removal of RM2.184 precipitable bands, OKM1 was still able to precipitate further p 165, 95 bands (Fig. 7). This observation indicates that expression of the epitope is co-dominant rather than dominant.

\section{Discussion}

These data show that RM2.184 recognizes a polymorphic determinant on CR3. The RM2.184 epitope is distinct from the alpha chain epitope recognized by OKM1. This conclusion is supported by the lack of mutual inhibition by the two MAb, the different susceptibilities of the epitopes to dissociation of the alpha and beta subunits, and the different effects of the two $\mathrm{MAb}$ on CR3 binding of EAC. It was not possible to directly determine the subunit localization of the RM2.184 epitope. However, this epitope is unlikely to be on the beta subunit, as there is strong evidence that this subunit is shared by CR3,
A

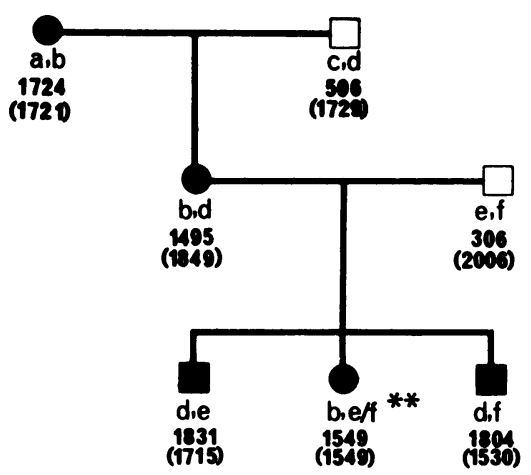

B

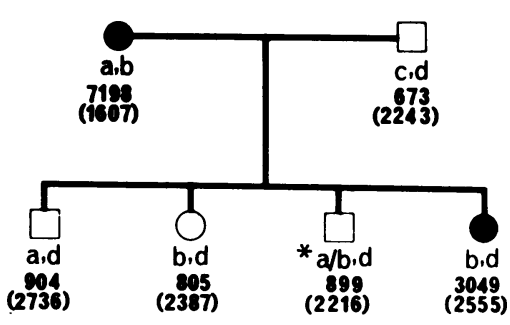

Figure 6. Segregation of RM2.184 and OKM1 (shown in brackets) binding assessed by the direct binding assay in three HLA genotyped families. Binding results are shown as raw cpm (mean of three replicates). The HLA haploytes are $A$ : a, A2, CW8, B14, DR blank; b, 2, 3, 60, 8; c, 1, 7, 8, 3; d, 28, 8, 14, 5; e, 3, 7, 7, 2; f, 2, 3, 62, 4. B: a, A2, B14, DR blank; b, 24, 7, 6; c, 3, 7, 2; d, 24, 44, 2. $C: \mathrm{a}, \mathrm{A} 3, \mathrm{~B} 13$, DRW6; b, $25,18,5$; c, 2, 62, 4, 29, 44, 7. *HLA A/B recombinant. ${ }^{* *}$ HLA-B/DR recombinant. 


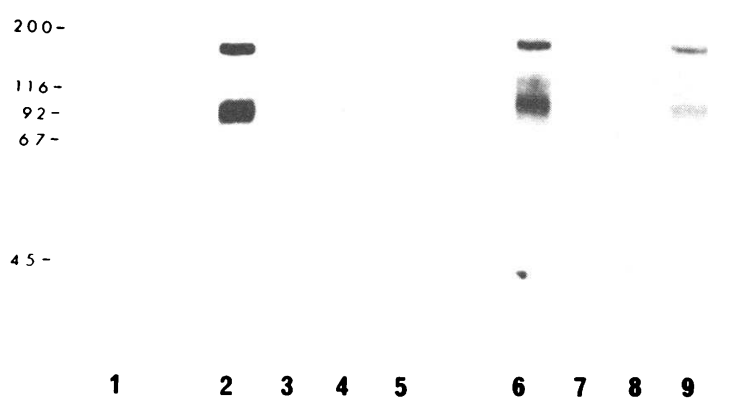

Figure 7. SDS-PAGE (7.5\% polyacrylamide gel) granulocyte lysates of a RM2.184 heterozygous subject. Lane 1 shows the precipitate produced by the control MAb 49-11.1. 2-4 show the results of sequential immunoprecipitation of one sample of lysate by OKM1 followed by RM2.184 (5). 6-9 show the results of three sequential immunoprecipitations of a sample of lysate by RM2.184 followed by OKM1.

LFA-1, and p 150, 95 (2), and anti-beta subunit MAbs have been demonstrated to precipitate all three alpha subunits. The inability of RM2.184 to bind to CR3 after the subunits have been separated by any of the methods attempted (electrophoresis, high $\mathrm{pH}$, or high urea concentration) suggests that the epitope is either very fragile or more probably is dependent on interaction between the alpha and beta subunits for its configuration. The issue of the relationship between the OKM1 epitope and the C3bi binding site is controversial $(2,6)$. The EAC used in this study may be capable of binding all types of complement receptors; however, because of the prolonged incubation of erythrocyte antibody IgM with the $\mathrm{R} 3$ reagent, most $\mathrm{C} 3 \mathrm{~b}$ would have been degraded. As granulocytes lack CR2 (23), rosette formation is predominantly due to CR3 binding of EAC3bi.

The results (Fig. 3) suggest that OKM1 epitope is closely related to the $\mathrm{C} 3 \mathrm{bi}$ binding site. However, the main importance of these experiments is that OKM1 and RM2.184 have different effects under identical conditions, and this finding supports the other evidence that the two epitopes are distinct. It will be of interest to determine the relationship between the RM2.184 and OKM9 epitopes, as OKM9 is also specific for CR3, and so likely to recognize an alpha subunit determinant, and it has been reported not to inhibit receptor-ligand binding (2). Similarly, it would be of interest to determine whether this polymorphism of CR3 is related to the HGA-1 antigen system common to granulocytes and monocytes defined by Thompson et al. (24) using allosera.

The frequency of the RM2.184 (+) phenotype is $\sim 14 \%$, and its segregation pattern in family studies is consistent with an autosomal dominant or co-dominant mode of inheritance (Fig. 6). However, sequential immunoprecipitation studies (Fig. 7) show that granulocytes of obligate heterozygotes carry both RM2.184 (+) and (-) CR3 molecules. This finding indicates a co-dominant rather than a dominant mode of inheritance.

Structural and qualitative polymorphisms of CR 1 have been described, and both are inherited in an autosomal co-dominant manner (25). The structural polymorphism of CR1 is detected by differences in molecular weight and electrophoretic mobility. These limited studies of the structural basis of the CR3 polymorphism have not demonstrated an obvious alteration of either parameter, and further study is required to establish its precise structural basis.

\section{Acknowledgments}

We thank Mrs. Rita Isaacs for expert technical assistance, Miss Sue Murphy and Mrs. Heather Churcher for monoclonal antibody production, Drs. McKenzie and Vadas for gifts of monoclonal antibodies, and Dr. A. Lopez for performing the fluoresence-activated cell sorter analyses.

These studies have been supported by a grant from the National Health and Medical Research Council of Australia.

\section{References}

1. Sanchez-Madrid, F., A. M. Krensky, C. F. Ware, E. Robbins, J. L. Stromonger, S. J. Burakoff, and T. A. Springer. 1982. Three distinct antigens associated with human T-lymphocyte-mediated-cytolysis; LFA1, LFA-2, and LFA-3. Proc. Natl. Acad. Sci. USA. 79:7489-7493.

2. Beller, D. I., T. A. Springer, and R. D. Schreiber. 1982. AntiMac-1 selectively inhibits the mouse and human type three complement receptor. J. Exp. Med. 156:1000-1009.

3. Sanchez-Madrid, F., J. A. Nagy, E. Robbins, P. Simon, and T. A. Springer. 1983. A human leukocyte differentiation antigen family with distinct subunits and a common subunit: the lymphocyte function-associated antigen (LFA-1), the C3bi complement receptor (OKMI/ Mac-1) and the p 150, 95 molecule. J. Exp. Med. 158:1785-1803.

4. Dana, N., R. F. Todd, J. Pitt, T. A. Springer, and M. Amin Arnaout. 1984. Deficiency of a surface membrane glycoprotein (MO1) in man. $J$. Clin. Invest. 73:153-159.

5. Amin-Arnaout, M., J. Pitt, H. J. Cohn, J. Melamed, R. S. Rosen, and H. R. Cotten. 1982. Deficiency of a granulocyte membrane glycoprotein (gp 150) in a boy with recurrent bacterial infections. N. Engl. J. Med. 306:693-699.

6. Wright, S. D., P. E. Rao, W. C. Van Voorhis, L. S. Graigmyle, I. Iida, M. A. Talle, E. F. Westberg, G. Goldstein, and S. C. Silverstein. 1983. Identification of the C3bi receptor of human monocytes and macrophages by using monoclonal antibodies. Proc. Natl. Acad. Sci. USA. 80:5699-5703.

7. Amin-Arnaout, M., R. F. Todd, N. Dana, J. Melamed, S. F. Schlossman, and H. R. Cotten. 1983. Inhibition of phagocytosis of complement C3- or immunoglobulin G-coated particles and of C3bi binding by monoclonal antibodies to a monocyte-granulocyte membrane glycoprotein (Mol). J. Clin. Invest. 72:171-179.

8. Russ, G. R., H. Churcher, M. Sato, A. d'Apice, W. Hancock, and B. Tait. 1984. A murine monoclonal antibody recognising a polymorphic determinant on monocytes and granulocytes. Transplant. Proc. 16:944945.

9. Boÿum, A. 1968. Isolation of mononuclear cells and granulocytes from human blood. Isolation of mononuclear cells by one centrifugation and of granulocytes by combining centrifugation and sedimentation at 1 g. Scand. J. Lab. Invest. 21 (Suppl.):77-89.

10. Danilovs, J. A., G. Ayoub, and P. I. Terasaki. 1980. B lymphocyte isolation by thrombin-nylon wool. Histocompatibility Testing 1980 . UCLA Tissue Typing Laboratory, Los Angeles. 287-288.

11. Köhler, G. 1981. The technique of hybridoma production. In Immunological Methods. II. I. Lefkovits and B. Pernis, editors. Academic Press, Inc., New York. 285-298.

12. Schulman, M., C. D. Wilde, and G. Köhler. 1978. A better cell line for making hybridomas secreting specific antibodies. Nature (Lond.). 276:269-270.

13. Staff, Research Resources Branch, NIAID. 1976. NIH Lymphocyte microcytotoxicity technique. In Manual of Tissue Typing Techniques. J. G. Ray, D. B. Hare, P. D. Peterson, and D. I. Mullally, editors. DHEW No. (NIH) 74-545:20. Washington, D.C. 22-24.

14. Hogarth, P. M., G. Edwards, I. F. C. McKenzie, J. W. Goding, and F. Y. Liew. 1982. Monoclonal antibodies to the murine Ly-2.1 all surface antigen. Immunology. 46:135-144.

15. Goding, J. W. 1980. Structural studies of murine lymphocyte surface IgD. J. Immunol. 124:2082-2088. 
16. Jones, P. P. 1980. Analysis of radiolabelled lymphocyte proteins by one- and two-dimensional polyacrylamide gel electrophoresis. In Selected Methods in Cellular Immunology. B. B. Mishell and S. M. Shiigi, editors. Freeman, Cooper \& Co., San Francisco. 398-440.

17. Swanstrom, R., and P. R. Shank. 1978. X-ray intensifying screens greatly enhance the detection by autoradiography of the radioactive isotopes ${ }^{32} \mathrm{P}$ and ${ }^{125} \mathrm{I}$. Anal. Biochem. 86:184-192.

18. Kurzinger, K., and T. A. Springer. 1982. Purification and structure characterization of LFA-1, a lymphocyte function-associated antigen, and Mac-1, a related macrophage differentiation antigen associated with the type three complement receptor. J. Biol. Chem. 257:12412-12418.

19. Gershoni, J. M., and G. E. Palade. 1983. Protein blotting. Anal. Biochem. 131:1-15.

20. Johnson, D. A., J. W. Gautsch, J. R. Sportsman, and J. H. Elder. 1984. Improved technique utilizing non fat dry milk for analysis of pro- teins and nucleic acids transferred to nitrocellulose. Gene Anal. Techn. 1:3-8.

21. Mason, D. W., and A. F. Williams. 1980. Kinetics of antibody binding to membrane antigen in solution and at the cell surface. Biochem. J. 187:1-20.

22. Lachmann, P. J., M. J. Hobart, and W. P. Aston. 1973. Complement Technology. Handbook of Experimental Immunology. D. M. Weir, editor. Blackwell Scientific Publications, Oxford. Second ed.

23. Fearon, D. T. 1984. Cellular receptors for fragments of the third component to complement. Immunol. Today. 5:105-110.

24. Thompson, J. S., V. L. Overlin, J. M. Herbick, C. D. Severson, F. H. J. Claas, J. D'Amaro, C. P. Burns, R. G. Strauss, and J. A. Koepke. 1980. New granulocyte antigens demonstrated by microgranulocytotoxicity assay. J. Clin. Invest. 65:1431-1439.

25. Fearon, D. T. 1984. Structure and function of the human C3b receptor. Fed. Proc. 43:2553-2557. 